\title{
Properties of the Ti-C-H-Cu composites obtained by mechanosynthesis using organic media
}

\author{
M. A. Eryomina ${ }^{1, \dagger}$, S. F. Lomayeva ${ }^{1}$, S. N. Paranin ${ }^{2}$, S. V. Zayatz ${ }^{2}$, V. V. Tarasov ${ }^{3}$, \\ I.S. Trifonov ${ }^{4}$ \\ †mrere@mail.ru
}

\begin{abstract}
${ }^{1}$ Physical Technical Institute Ural Branch of RAS, 132 Kirova str., 426000, Izhevsk, Russia ${ }^{2}$ Institute of Electrophysics Ural Branch of RAS, 106 Amundsen str., 620216, Yekaterinburg, Russia

${ }^{3}$ Institute of Mechanics, Ural Branch of RAS, 34 T. Baramzinoy str., 426067, Izhevsk, Russia

${ }^{4}$ Kalashnikov Izhevsk State Technical University, 7 Studencheskaya str., 426069, Izhevsk, Russia
\end{abstract}

Composites of a Ti-C-H-Cu system were obtained by mechanosynthesis in liquid carbon media (petroleum ether, xylene) followed by magnetic pulse compaction of the powders at $500^{\circ} \mathrm{C}$ in vacuum with the pressure amplitude of about $1.5 \mathrm{GPa}$. The chosen proportion of the components ( $\mathrm{Ti}, \mathrm{Cu}$ ) corresponded to the composition $\mathrm{TiC}(90 \mathrm{vol} \%)-\mathrm{Cu}(10 \mathrm{vol} \%)$. In addition, composites containing $\mathrm{Cr}$ and/or $\mathrm{Ni}$ with the atomic ratio of concentrations $\mathrm{Cu}$ : (Cr,Ni) equal to 80:20 were obtained. The compacts obtained had the diameter of $10 \mathrm{~mm}$ and thickness of 3 to $5 \mathrm{~mm}$. The structure and phase composition of the composites were studied and density, microhardness and wear resistance were determined. The composites processed had the density of $87-95 \%$ of the theoretical value. The mechanosynthesis process in petroleum ether is not complete in $3 \mathrm{~h}$, since in the phase composition of compacts one observes, apart from intermetallic phase $\mathrm{CiTi}_{2}$ and titanium carbohydride $\mathrm{Ti}_{2} \mathrm{CH}_{0.6}$, a significant amount of the initial Ti. The composites exhibit a layered microstructure. Use of xylene for mechanosynthesis process of the same duration allows one to obtain two-phase composites $\mathrm{Ti}_{2} \mathrm{CH}_{0.6}+\mathrm{CuTi}_{2}$. An increase of the duration of mechanical treatment up to $6 \mathrm{~h}$ leads to a formation of intermetallic $\mathrm{CuTi}$ in the phase composition of the composites obtained. Use of xylene allows one to obtain also $10-20 \mathrm{vol} \%$ of nonstoichiometric carbide TiC. The microhardness of about $5 \mathrm{GPa}$ was obtained for all the composites studied. Abrasive wear of the composites is an order of magnitude lower than that of steel U13. Alloying with $\mathrm{Ni}$ and/or $\mathrm{Cr}$ leads to some decrease of wear resistance due to a decrease of the quantity of TiC phase.

Keywords: titanium carbohydride, copper, mechanosynthesis, magnetic-pulse compaction, wear resistance.

\section{Свойства композитов Тi-C-H-Cu, механосинтезированных с использованием органических сред}

\author{
Ерёмина М. А. ${ }^{1 \dagger}$, Ломаева С. Ф. ${ }^{1}$, Паранин С. Н. ${ }^{2}$, Заяц С. В. ${ }^{2}$, Тарасов В. В. ${ }^{3}$, \\ Трифонов И.С. ${ }^{4}$ \\ †mrere@mail.ru

\footnotetext{
${ }^{1}$ Физико-технический институт УрО РАН, ул. Кирова 132, 426000, Ижевск, Россия ${ }^{2}$ Институт электрофизики УрО РАН, ул. Амундсена 106, 620216, Екатеринбург, Россия

${ }^{3}$ Институт механики УрО РАН, ул. Т. Барамзиной 34, 426067, Ижевск, Россия

${ }^{4}$ Ижевский государственный технический университет им. М. Т. Калашникова, ул. Студенческая 7, 426069, Ижевск, Россия
}

Механосинтезом в жидких углеводородных средах (петролейный эфир, ксилол) и последующим магнитно-импульс-
ным прессованием порошков при $500^{\circ} \mathrm{C}$ в вакууме при амплитуде импульсов давления 1.5 ГПа получены компо-
зиты системы Ti-C-H-Cu. Для исследования выбраны концентрации Ті и Сu, обеспечивающие состав композита
$\mathrm{TiC}(90$ об.\%)- $\mathrm{Cu}(10$ об.\%). Помимо этого получены композиты, легированные $\mathrm{Cr}$ и/или $\mathrm{Ni}$, с соотношением
$\mathrm{Cu}(\mathrm{Cr}, \mathrm{Ni})$ равным 80:20. Диаметр полученных компактов -10 мм, толщина $-3-5$ мм. Исследовано структур-
но-фазовое состояние композитов, определены их плотность, микротвёрдость и абразивная износостойкость. По- 
лученные композиты имеют плотность 87 -95\% от теоретического значения. Механосинтез в петролейном эфире в течение 3 ч протекает недостаточно полно, так как при последующем компактировании в фазовом составе композита помимо фаз интерметаллида $\mathrm{CuTi}_{2}$ и карбогидрида титана $\mathrm{Ti}_{2} \mathrm{CH}_{0.6}$ наблюдается значительная доля исходного титана. Композиты имеют слоистую микроструктуру. Механосинтез в ксилоле в течение того же времени позволяет получать композиты с двухфазной структурой $\mathrm{Ti}_{2} \mathrm{CH}_{0.6}+\mathrm{CuTi}_{2}$. Увеличение времени механообработки до 6 ч приводит к появлению в составе полученных образцов интерметаллида СuTi. Механосинтез в ксилоле позволяет также получить 10 - 20 об.\% фазы нестехиометрического карбида титана ТiС с решёткой, обеднённой углеродом. Микротвёрдость всех полученных композитов, независимо от их химического и фазового составов, составляет 5 ГПа. Величина абразивного износа на порядок ниже, чем для стали У13. Легирование Ni и/или Cr приводит к некоторому ухудшению износостойкости вследствие снижения доли ТiС.

Ключевые слова: карбогидрид титана, медь, механосинтез, магнитно-импульсное прессование, износостойкость.

\section{1. Введение}

Свойства твёрдых сплавов на основе карбида титана в значительной степени зависят от технологии их производства. Наилучший уровень свойств достигается при уменьшении зерна карбида [1]. Для получения гомогенной смеси ультрадисперсного $\mathrm{TiC}$ со связующим компонентом используют технологии механохимической активации [2-5]. Для уменьшения загрязнения карбида титана материалом мелющих тел в активируемую смесь порошков вводят жидкую фазу [3]. Механосинтезом (MC) титана и углерода в присутствии жидкого углеводорода получают метастабильные г.ц.к. твердые растворы углерода и водорода в титане, которые при последующей термообработке распадаются с образованием однофазных (ТiC) или двухфазных смесей $(\mathrm{TiC}+\alpha-\mathrm{Ti})[6-9]$. В работах [7-9] помимо линий $\mathrm{TiC}$ и $\alpha$-Ti на дифрактограммах отожженных порошков присутствуют линии неидентифицированной фазы. Анализ данных [10-12] показал, что эти линии относятся, вероятнее всего, к фазе гексагонального карбогидрида титана, который обладает достаточно высокой термической стабильностью. Ранее данную фазу получали только методами СВС и высокотемпературного спекания [10-12]. Использование жидкофазного МС может позволить получать карбиды и карбогидриды титана в связках из любых переходных металлов. Медь, легированная дисперсными добавками переходных металлов, эффективно заменяет дорогостоящую и токсичную кобальтовую связку в твердых сплавах. Легирование медной связки хромом и никелем способствует повышению прочности и коррозионной стойкости сплавов. К тому же при МС титана с медью, хромом и никелем могут формироваться интерметаллидные фазы, которые также способствуют повышению прочности, твердости и износостойкости как связки, так и композита в целом. Фазообразование при МС в системе Ti-C-H-Cu, а также структурно-фазовое состояние и свойства компактированных образцов остаются не изученными.

Целью работы было изучение структурно-фазового состава композитов $\mathrm{Ti}-\mathrm{C}-\mathrm{Cu}(\mathrm{Ni}, \mathrm{Cr})$, полученных механосинтезом в органических средах (петролейный эфир, ксилол) и последующим магнитно-импульсным прессованием порошков, и оценка их свойств - плотности, микротвёрдости и износостойкости.

\section{2. Образцы и методы}

Для исследования выбраны концентрации $\mathrm{Ti}, \mathrm{Cu}, \mathrm{Cr}$ и $\mathrm{Ni}$, обеспечивающие состав композита $\mathrm{TiC}(90$ об.\%) - $\mathrm{Cu}(\mathrm{Ni}, \mathrm{Cr})(10$ об.\%). Соотношение меди к общему содержанию хрома и/или никеля составляло 80:20. Синтез проводили в шаровой планетарной мельнице “Fritsch P-7". Контейнеры и размольные шары изготовлены из стали ШХ15. Использовали порошки титана (99.02 вес.\%), меди (99.72 вес.\%), никеля (99.50 вес.\%) и хрома (99.92 вес.\%). Контейнеры полностью заполняли петролейным эфиром или ксилолом, время механосинтеза - 3 и 6 ч. Образцы, полученные в петролейном эфире, обозначены Р3 и Р6 (цифра соответствует длительности механосинтеза), в ксилоле - Х3 и Х6, легированные никелем - X6Ni, хромом - X6Cr, никелем и хромом - X6NiCr. Магнитно-импульсное прессование проводили при $500^{\circ} \mathrm{C}$ в вакууме (остаточное давление 5-10 Па), с предварительной дегазацией в течение 4 ч. Амплитуда импульсов давления составляла 1.5 ГПа, длительность - 300 мкс. Структурно-фазовое состояние образцов оценивали методом рентгеновской дифракции на дифрактометре MiniFlex (Rigaku) в Со-K $\mathrm{K}_{\alpha}$ излучении. Оценка микроструктурного состояния образцов проводилась на электронном микроскопе VEGA 3 LMN (TESCAN) с системой рентгеновского энергодисперсионного микроанализа INCA Energy 250/X-max 20 (Oxford Instruments) при ускоряющем напряжении 20 кВ с предварительным химическим травлением полированных образцов. Измерения плотности прессовок проведены гидростатическим и геометрическим методами. Микротвёрдость по Виккерсу определена на приборе ПМТ-3 по десяти измерениям при нагрузке 100 г. Исследования абразивной износостойкости проводили на трёхкоординатном фрезерном станке с ЧПУ “КХЗА” (Profi, Германия) [13] с использованием электрокорундовых шкурок на тканевой основе КК19XW с разным размером частиц абразива M40 (28-40 мкм), 4-Н (40-50 мкм) и 5-Н (50-63 мкм). Длина пути движения образца составляла 285 мм, скорость поступательного перемещения - 750 мм/мин, частота вращения вокруг своей оси -750 мин $^{-1}$. Удельная нагрузка составляла около $0.014 \mathrm{H} / \mathrm{Mм}^{2}$. Массовый износ определяли как среднее значение по трём измерениям на аналитических весах ВЛА-200г-М. Погрешность определения массы \pm 2 мг. Для сравнения при тех же условиях получены величины износостой- 
кости образцов из промышленных материалов: стали У13 (St13) и сплава Т5К10 (85 вес.\% WC, 6 вес.\% TiC, 9 вес.\% Co).

\section{3. Результаты и обсуждение}

В фазовом составе полученных композитов (рис. 1 и табл. 1) присутствуют интерметаллиды $\mathrm{CuTi}$ и $\mathrm{CuTi}_{2}$, а также фазы карбида $(F m 3 m)$ и карбогидрида титана $\mathrm{Ti}_{2} \mathrm{CH}_{0.6}$ с пространственной структурой $P-3 m 1$. В композите, полученном в петролейном эфире в течение 3 часов, сохранился титан, что свидетельствует о незавершенности процесса механосинтеза карбогидрида титана. Механосинтез в ксилоле в течение того же времени позволяет получать композиты с двухфазной структурой $\mathrm{Ti}_{2} \mathrm{CH}_{0.6}+\mathrm{CuTi}_{2}$. При увеличении времени синтеза до 6 ч, помимо $\mathrm{Ti}_{2} \mathrm{CH}_{0.6}$ и $\mathrm{CuTi}_{2}$ появляются фазы $\mathrm{CuTi}, \mathrm{TiC}$ и $\alpha$-Fe. Процесс механосинтеза в ароматических углеводородах (ксилол) идет более интенсивно [14], что позволяет получить композиты, в составе которых наряду с карбогидридом присутствуют и карбид титана. Параметр кубической решётки карбида титана (0.4286-0.4290 нм) существенно снижен относительно значения для стехиометрического $\mathrm{TiC}$ (0.4328 нм) вследствие недостатка углерода. Легирование никелем и/или хромом приводит к снижению доли ТiC.

На рис. 2a-2c приведены электронно-микроскопические изображения поверхности композита, полученного при механосинтезе в петролейном эфире в течение 3 часов. По краям круглого образца заметна пористость, центр выглядит достаточно плотным (рис. 2a,b). Композит имеет слоистую микроструктуру (рис. 2c): светлые слои интерметаллида $\mathrm{CuTi}$ чередуются с более тёмными слоями карбогидрида $\mathrm{Ti}_{2} \mathrm{CH}_{0.6}$. Толщина слоёв в среднем составляет 50 - 100 нм. В табл. 2 показан химический состав разных участков поверхности. Усреднённое по поверхности соотношение $\mathrm{Ti}: \mathrm{Cu}$ соответствует заложенному, однако содержание углерода явно недостаточно для образования стехиометрического $\mathrm{TiC}$.

Плотность и микротвёрдость композитов приведены в табл. 3. На основании результатов количественного фазового анализа и известных величин плотности отдельных фаз были рассчитаны значения теоретической и относительной плотностей композитов. Плотность

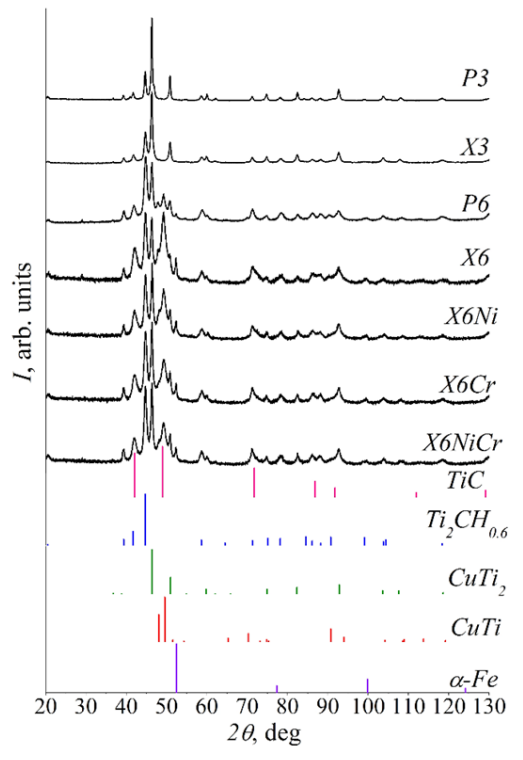

Рис. 1. Рентгеновские дифрактограммы.

Fig. 1. X-ray diffraction patterns.

Табл. 1. Фазовый состав (об.\%) образцов.

Table 1. Phase composition (vol\%) of samples.

\begin{tabular}{|c|c|c|c|c|c|c|}
\hline \multirow{2}{*}{$\begin{array}{c}\text { образец } \\
\text { sample }\end{array}$} & \multicolumn{7}{|c|}{ об.\%/vol\% } \\
\cline { 2 - 7 } & $\alpha$-Ti & $\mathrm{TiC}$ & $\mathrm{Ti}_{2} \mathrm{CH}_{0.6}$ & $\mathrm{CuTi}_{2}$ & $\mathrm{CuTi}$ & $\alpha$-Fe \\
\hline $\mathrm{P} 3$ & 17 & 0 & 53 & 30 & 0 & 0 \\
\hline $\mathrm{P} 6$ & 0 & 0 & 77 & 14 & 9 & 0 \\
\hline $\mathrm{X} 3$ & 0 & 0 & 66 & 34 & 0 & 0 \\
\hline $\mathrm{X} 6$ & 0 & 21 & 55 & 11 & 12 & 1 \\
\hline $\mathrm{X} 6 \mathrm{Ni}$ & 0 & 14 & 60 & 13 & 12 & 1 \\
\hline $\mathrm{X} 6 \mathrm{Cr}$ & 0 & 13 & 63 & 14 & 9 & 1 \\
\hline $\mathrm{X} 6 \mathrm{NiCr}$ & 0 & 9 & 67 & 13 & 10 & 1 \\
\hline
\end{tabular}

Табл. 2.Состав (вес.\%) в разных областях (см. рис. 3) поверхности образца Р3.

Table 2. Composition (wt $\%$ ) of different parts of surface of the sample P3 (see Fig. 3).

\begin{tabular}{|c|c|c|c|c|c|c|}
\hline \multirow{2}{*}{$\begin{array}{c}\text { исх. } \\
\text { init. }\end{array}$} & 66.5 & 16.8 & - & - & - & $80: 20$ \\
\cline { 2 - 7 } & $6 \mathrm{Ti}$ & $\mathrm{Cu}$ & $\mathrm{C}$ & $\mathrm{Fe}$ & $\mathrm{O}$ & $\mathrm{Ti}: \mathrm{Cu}$ \\
\hline $\mathbf{1}$ & 65.4 & 24.2 & 7.4 & 3.0 & - & $73: 27$ \\
\hline $\mathbf{2}$ & 73.4 & 18.3 & 7.0 & 0.8 & 0.5 & $80: 20$ \\
\hline $\mathbf{3}$ & 39.2 & 8.4 & 30.4 & 1.2 & 20.8 & $82: 18$ \\
\hline
\end{tabular}

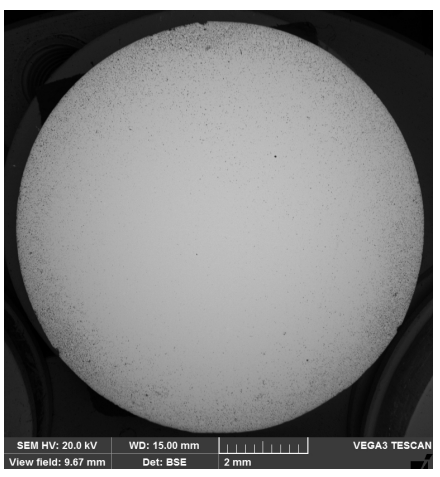

a

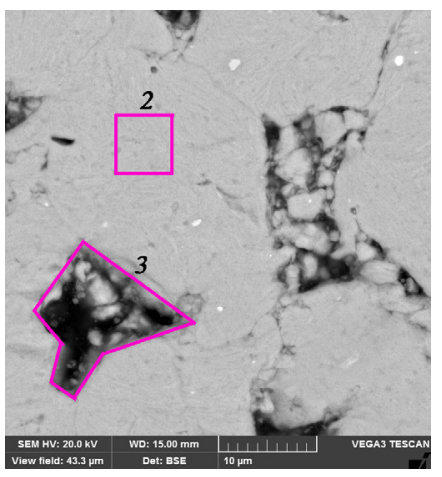

$\mathrm{b}$

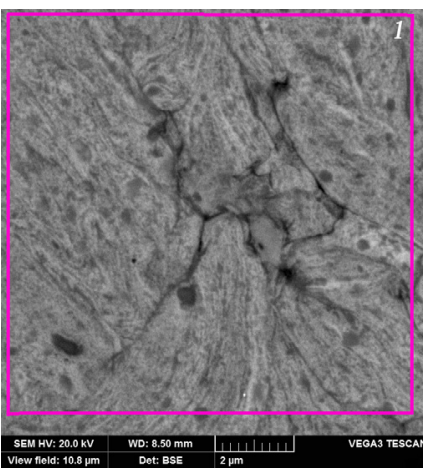

c

Рис. 2. Электронно-микроскопические изображения (а) всей поверхности композита Р3, (b) его края и (c) центральной части. Fig. 2. SEM images of the (a) whole surface of P3 composite, its (b) border and (c) central parts. 
Табл. 3. Плотность и микротвёрдость образцов. Table 3. Density and microhardness of the samples.

\begin{tabular}{|c|c|c|c|}
\hline $\begin{array}{c}\text { образец } \\
\text { sample }\end{array}$ & $\rho\left(\mathrm{g} / \mathrm{cm}^{3}\right)$ & $\rho(\%)$ & $H V(\mathrm{GPa})$ \\
\hline $\mathrm{P} 3$ & $4.60(5)$ & 95 & $5.1(8)$ \\
\hline $\mathrm{P} 6$ & $4.51(5)$ & 94 & $4.4(3)$ \\
\hline $\mathrm{X} 3$ & $4.44(5)$ & 91 & $4.9(4)$ \\
\hline $\mathrm{X} 6$ & $4.41(5)$ & 89 & $5.2(5)$ \\
\hline $\mathrm{X} 6 \mathrm{Ni}$ & $4.39(5)$ & 88 & $5.0(4)$ \\
\hline $\mathrm{X} 6 \mathrm{Cr}$ & $4.29(5)$ & 87 & $4.7(3)$ \\
\hline $\mathrm{X} 6 \mathrm{NiCr}$ & $4.28(5)$ & 88 & $4.4(4)$ \\
\hline
\end{tabular}

составляет 87-95\% от теоретических значений. Микротвёрдость композитов 4.4-5.2 ГПа ниже, чем микротвёрдость промышленного сплава Т5К10 -14 ГПа. По-видимому, меньшая микротвёрдость объясняется свойствами самой фазы карбогидрида титана. Литературных данных по микротвёрдости карбогидридов титана не найдено.

Значения величин абразивного износа композитов (рис. 3) в среднем в десять раз ниже значений для стали У13 и в сорок раз больше значений для твёрдого сплава Т5К10. По-видимому, меньшая износостойкость полученных композитов по сравнению со сплавом Т5К10 обусловлена, прежде всего, природой фазы гексагонального карбогидрида титана. Более низкие величины износа получены для композитов, синтезированных в течение 6 ч, что связано с меньшей долей интерметаллидных фаз и большей долей карбогидрида. Уровень износостойкости композитов не чувствителен к изменению количества Fе. При введении $\mathrm{Ni}$ и/или $\mathrm{Cr}$ наблюдается снижение доли ТіС при одновременном росте доли $\mathrm{Ti}_{2} \mathrm{CH}_{0.6}$, что способствует ухудшению износостойкости.

\section{4. Заключение}

Механосинтезом в жидких органических средах (предельном углеводороде - петролейном эфире и ароматическом углеводороде - ксилоле) с последующим магнитно-импульсным прессованием получены композиты $\left(\mathrm{Ti}_{2} \mathrm{CH}_{0.6}, \mathrm{TiC}\right)+\left(\mathrm{CuTi}_{2}, \mathrm{CuTi}\right)$ с микротвёрдостью $\sim 5$ ГПа и с уровнем износостойкости на порядок выше, чем для стали У13.

Увеличение длительности механообработки способствует увеличению доли фазы $\mathrm{Ti}_{2} \mathrm{CH}_{0.6}$ и, соответственно, снижению доли интерметаллидных фаз, что приводит к повышению износостойкости. Легирование $\mathrm{Cr}$ и/или $\mathrm{Ni}$ приводит к уменьшению доли $\mathrm{TiC}$ и снижению износостойкости. Присутствие до 3 вес.\% железа не влияет на показатели микротвёрдости и износостойкости.

Благодарность/Aknowledgements. Работа выполнена в рамках гос. задания ФАНО России, № гос. регистраиии НИР АААА-А17-117022250038-7, частично поддержана Программой Президиума УрО РАН, № 15-17-12-26.

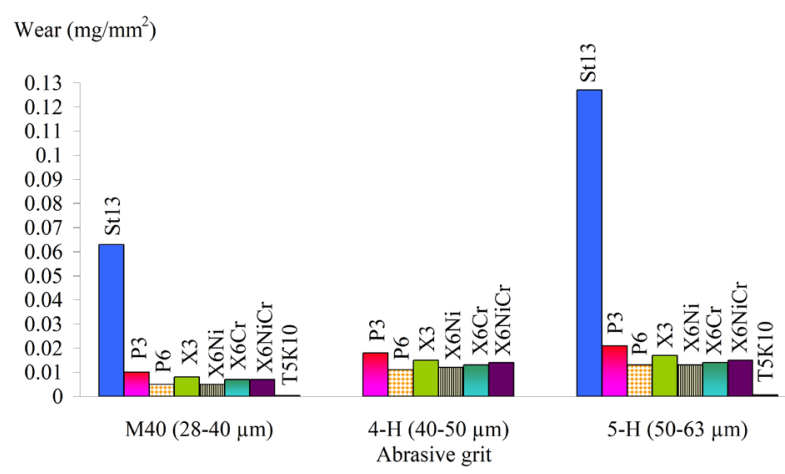

Рис. 3. Диаграммы износа композитов.

Fig. 3. Wear resistance diagrams of the composites.

\section{Литература/References}

1. A.K. Garbuzova, G. V. Galevsky, V.V. Rudneva, L.S. Shiryaeva. Vestn. Sib. Industr. Univ. 1(7), 34 (2014). (in Russian) [А.К. Гарбузова, Г.В. Галевский, В. В. Руднева, Л. С. Ширяева. Вестн. Сиб. гос. индустр. унив. 1(7), 34 (2014).]

2. B.H. Lohse, A. Calka, D. Wexler. J. Mater. Sci. 42, 669 (2007), DOI: 10.1007/s10853-006-0291-5

3. S.-M. Hong, J.-J. Park, E.-K. Park, K.-Y. Kim, J.-G. Lee, M.-K. Lee, Ch.-K. Rhee, J.K. Lee. Powd. Technol. 274, 393 (2015), https://doi.org/10.1016/j.powtec.2015.01.047

4. L. L. Ye, and M.X. Quan. NanoStruct. Mater. 5(1), 25 (1995), https://doi.org/10.1016/0965-9773(95)00012-4

5. M. Sherif El-Eskandarany. J. Alloys Compnd. 305, 225 (2000), https://doi.org/10.1016/S0925-8388(00)00692-7

6. T. Suzuki, M. Nagumo. Scr. Metall. Mater. 27(10), 1413 (1992), https://doi.org/10.1016/0956-716X(92)90093-T

7. T. Suzuki, M. Nagumo. Scr. Metall. Mater. 32(8), 1215 (1995), https://doi.org/10.1016/0956-716X(95)00128-I

8. M. Nagumo, T. Suzuki, and K. Tsuchida. Mater. Sci. Forum Vols. Trans. - Switzerland: Tech. Publications. 225-227, 581 (1996), DOI:10.4028/www.scientific.net/MSF.225-227.581

9. M. Nagumo. Mater. Trans., JIM. 36 (2), 170 (1995), http://doi.org/10.2320/matertrans1989.36.170

10. J. Rexer. Ternary metal-carbon-hydrogen compounds of some transition metals. Retrospective theses and dissertations. Paper 2073, 44 (1962).

11. I. Khidirov, B.B. Mirzaev, N.N. Mukhtarova, Kh.M. Kholmedov, S. Yu. Zaginaichenko, D. V. In: B. Baranowski, S.Y. Zaginaichenko, D. V. Schur, V.V. Skorokhod, A. Veziroglu (eds) Carbon Nanomaterials in Clean Energy Hydrogen Systems. NATO Science for Peace and Security Series C: Environmental Security. Springer, Dordrecht, 663 (2007), DOI: 10.1007/978-1-4020-8898-8_83

12. I. Khidirov. Russ. J. Inorg. Chem. 62(4), 498 (2017).

13. V.V. Tarasov, S. Yu. Lokhanina, A. V. Churkin. Diagn. Mater. 76(4), 57 (2010). (in Russian) [В.В. Тарасов, С. Ю. Лоханина, А. В. Чуркин. Зав. лаб. Диагн. матер. 76(4), 57 (2010).]

14. S.F. Lomayeva. Phys. Met. Metallogr. (in Russian) [С.Ф. Ломаева. Физ. Мет. Металловед. 104(4), 403 (2007).], DOI: 10.1134/S0031918X07100092 